\title{
Platelet-Activating Factor Reduces Caspase-3 Activity and Enhances Embryo Development in the Sea Urchin (Lytechinus variegatus)
}

\author{
Arnav Lal, Jonathan Blalock, Renee J Chosed and William E Roudebush* \\ Department of Biomedical Sciences, University of South Carolina School of Medicine Greenville, USA
}

\begin{abstract}
Introduction: Understanding early embryonic growth and development in the sea urchin model is beneficial for understanding similar events for human embryos Many environmental and external factors impact embryo growth/development and physiological processes, such as apoptosis. Furthermore, several endogenous molecules impact embryo development such as embryo-derived growth factors, e.g. platelet-activating factor (PAF). PAF is a potent signaling phospholipid produced by human gametes and early embryos and is required for fertilization and subsequent development. Exogenous PAF has been used for enhanced fertilization and embryo development, however, the mechanism and process by which PAF improves development has not been fully elucidated. In other systems, PAF modulates apoptosis activity, both by inhibition and activation. Therefore, this study utilized the sea urchin to investigate PAF's extent of action during early embryo development.

Methods: Two-cell stage sea urchin embryos were cultured (20 embryos/replicate; 6 replicates per treatment group) in synthetic sea water ( $50 \mathrm{~mL})$ and in the presence or absence (control group) of $10^{-7} \mathrm{M}$ PAF. Following a 24-hour culture period at $22^{\circ} \mathrm{C}$, embryo development was recorded and caspase-3 activity, one measure of apoptotic activity, was assessed by monitoring cleavage of DEVD-AMC peptide substrate. Cleavage of the DEVD-AMC peptide by sea urchin embryonic extracts was determined by measuring fluorescence at $360 / 405 \mathrm{~nm}$ by detecting absolute fluorescence (reported in AFU) over time (once per minute for a total of 30 minutes).

Results: There was a significant $(\mathrm{P}<0.01)$ difference in overall embryo development between sea urchin embryos cultured in $\mathrm{PAF}(99.2 \%)$ versus controls $(89.2 \%)$. The PAF group $(55.8 \%)$ had significantly $(\mathrm{P}<0.01)$ more late-stage (gastrula) embryos than the control group $(16.7 \%)$. There was also a significant difference $(\mathrm{P}<0.05)$ in caspase-3 enzyme activity between sea urchin embryos cultured in PAF (1.25 [AFU/minute]) versus controls (2.19 [AFU/minute)

Conclusion: Exogenous PAF introduced to the sea urchin embryo resulted in reduced caspase- 3 activity and higher stages of development. Moreover, sea urchin embryos exposed to PAF exhibited lower levels of apoptosis, as demonstrated by the significantly lower rate of substrate cleavage by extracts. Further studies will elucidate the mechanism by which PAF reduces apoptosis to promote early embryonic development.
\end{abstract}

\section{Introduction}

Approximately $15 \%$ of reproductive age couples are affected by infertility, and the numbers continue to rise [1]. Unfortunately, infertility has become stigmatized and oftentimes leads to discrimination, depression, and ostracism [2]. With changing cultural norms pushing pregnancies to later ages, an increase in obesity, smoking, alcohol, and drugs as well as environmental pollution deteriorating male fertility rates, the number of infertile couples is only bound to increase aggressively [3]. While in vitro fertilization (IVF) is an option for couples, rates of successful implantation and live birth still only hover around $50 \%$, decreasing in chance with age and other complications [4]. Given the increasing infertility, the use of IVF continues rise, and therefore enhancing IVF methods holds significant value.

Problems in IVF outcomes may arise when embryos fail to develop in culture and fail uterine implantation. While procedures in IVF require assessing the quality of oocytes and sperm and subsequent actions employ these results, there still remains mystery over why certain embryos fail to develop and implant $[5,6]$. Uncovering the molecular mechanisms that regulate early embryo development is crucial to understanding why implantation of IVF generated embryos does not always result in a live birth. Furthermore, endogenous and exogenous elements impact human embryo development such as embryo-derived growth factors [7].
One such embryo-derived growth factor is platelet-activating factor (PAF: 1-alkyl, 2-acetyl phosphatidylcholine), a potent signaling phospholipid produced by human gametes and early embryos, which is also required for fertilization and subsequent development [8]. Exogenous PAF has been used for enhanced fertilization and embryo development, however, the mechanism or the extent by which PAF improves development in embryology has not been fully elucidated [9]. In other biological systems, PAF modulates apoptosis activity, both by inhibition and activation of the apoptosis pathways, and serves multiple roles in additional biochemical pathways $[10,11]$.

The regulation of apoptosis by PAF provides a viable opportunity to develop a hypothesis correlating PAF to embryo development rates. The fact that apoptosis plays a major role in embryo development

${ }^{*}$ Correspondence to: William E. Roudebush, $\mathrm{PhD}$; Department of Biomedical Sciences, University of South Carolina School of Medicine Greenville, Greenville, South Carolina 29605 USA, Tel: 864-455-9833; E-mail: roudebus@ greenvillemed.sc.edu

Key words: Platelet-activating Factor, Sea Urchin, Apoptosis, Caspase-3, Embryo development

Received: January 28, 2019; Accepted: February 04, 2019; Published: February 07,2019 
[12]. Apoptosis, known as programmed cell death, occurs during preimplantation embryo development and possibly serves as a corrective mechanism, sacrificing cells for overall embryo competence [13]. The regulation of the apoptosis pathway during development may serve as a reason for understanding potential differences in embryo quality during our experimentation. Moreover, we utilized the activity of caspase 3, a caspase protein that plays a paramount role in the execution of cell apoptosis, to quantitively assess any differences in apoptosis which exogenous PAF initiated [14].

To understand the implications of exogenous PAF treatment and observe the resulting levels of apoptosis, we selected a marine model organism. Marine invertebrates, such as the sea urchin, are a timehonored model for investigational studies throughout developmental biology. Moreover, sea urchin embryos undergo apoptosis via the enzymatic activity of caspases and other proteins similar as human embryo [15]. Due to this similarity, understanding early embryonic growth and development in the sea urchin model is beneficial for understanding similar events for human embryos. Therefore, this study utilized the sea urchin to investigate PAF's mechanism of action during early embryo development. Extensive study of PAF through a sea urchin model may uncover additional methods to improve IVF live birth rates.

\section{Materials and Methods}

Individual Lytechinus variegatus sea urchins were injected with 0.5 $\mathrm{mL} \mathrm{KCl}(0.5 \mathrm{M})$ to induce gamete shedding and pooled accordingly. Oocytes were inseminated with spermatozoa in synthetic sea water and cultured (for approximately 90 minutes) to produce two-cell stage embryos. The two-cell stage embryos were selected and cultured (20 embryos/replicate; 6 replicates per treatment group) in synthetic sea water $(50 \mu \mathrm{L})$ in the presence or absence (control group) of $10^{-7} \mathrm{M}$ plateletactivating factor (PAF; Fertility Genomics, Marietta, GA). Following a 24 -hour culture period at $22^{\circ} \mathrm{C}$, embryo development (blastopore, blastula and gastrula stages) was recorded and each replicate group were collected and stored at $-80^{\circ} \mathrm{C}$. Each individual replicate group was frozen and subsequently thawed three times to induce cellular lysis. Following cellular lysis, each frozen/thawed replicate group was centrifuged (1,000g; 5 minutes) and an aliquot of the aqueous phase was assayed for caspase- 3 activity by monitoring cleavage of the DEVD-AMC peptide substrate (known caspase-3 specific substrate) per manufacturer's instructions (Enzo Life Science, Farmingdale, NY). Briefly, $10 \mu \mathrm{L}$ of the sea urchin embryonic extract was placed in buffer in a 96 -well plate and $40 \mu \mathrm{L}$ DEVD-AMC peptide was added to each well. Cleavage of the substrate by caspase-3 present in the sea urchin embryonic extract was detected by measuring absolute fluorescence (reported as AFU) at $420-460 \mathrm{~nm}$ wavelength range (Tecan Infinite M1000 plate reader). The emission from each sea urchin extract group was measured over a total of 30 minutes and AFUs were plotted (time vs AFU) and then the slope was calculated once the background from buffer emission was subtracted from the total value.

\section{Results}

Morphological and developmental differences were observed between the sea urchin L. variegatus embryos cultured in exogenous $\mathrm{PAF}$ and controls. There was a significant $(\mathrm{P}<0.01$; Figure 1$)$ difference in overall embryo threshold development (indicated by the embryo reaching the blastopore, blastula, and gastrula stages of development) between sea urchin embryos cultured in PAF (99.2\%) versus controls (89.2\%), considering approximately 120 embryos per group. Also, of those embryos which developed at least into the blastula phase, the PAF group (55.8\%) had significantly $(\mathrm{P}<0.01$; Figure 2$)$ more late-stage (gastrula) embryos than the control group (16.7\%), which contained far more mid-stage (blastula) embryos.

Moreover, biochemical differences were also detected within the two groups. When considering the average rate of caspase-3

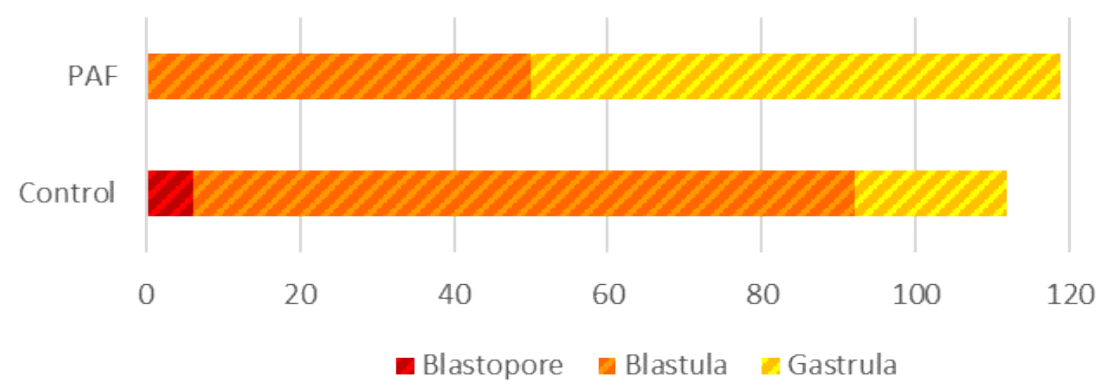

Figure 1. Sea Urchin embryo development differs in embryos cultured in PAF. There was a significant $(\mathrm{P}<0.01)$ difference in overall embryo development between sea urchin embryos cultured in PAF (99.2\%) versus controls (89.2\%). For the surviving embryos, the levels of development varied per treatment group

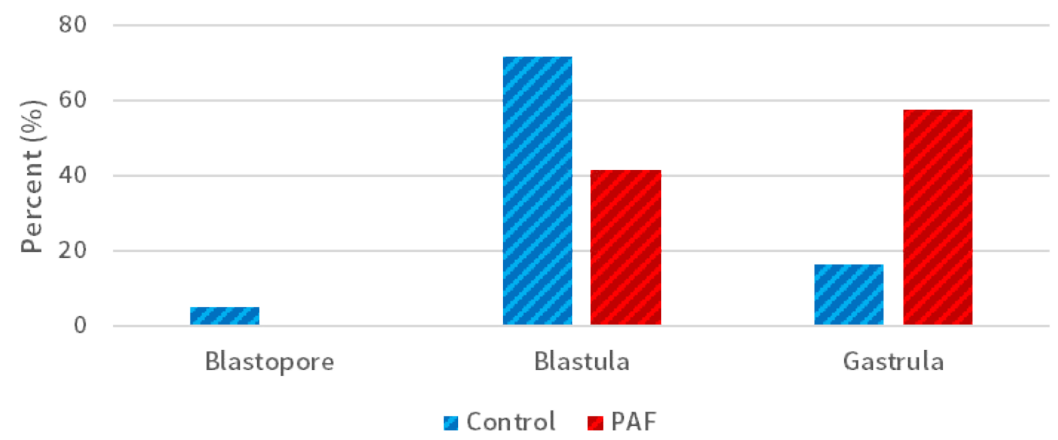

Figure 2. Sea urchin development rates in the PAF and control groups. The group of embryos cultured in PAF (55.8\%) had significantly (P<0.01) more late-stage (gastrula) embryos than the control group $(16.7 \%)$ 
enzyme activity, there was a significant difference $(\mathrm{P}<0.05$; Figure 3 ) between sea urchin embryos cultured in exogenous PAF $(33.5$ [AFU/minute]) versus controls (43.8 [AFU/minute]) in each group. As a follow-up, the time-dependent graph (Figure 4) analyzing the caspase- 3 enzyme activity demonstrated a continually present difference in numerical value signifying enzyme activity throughout the 30 minutes.

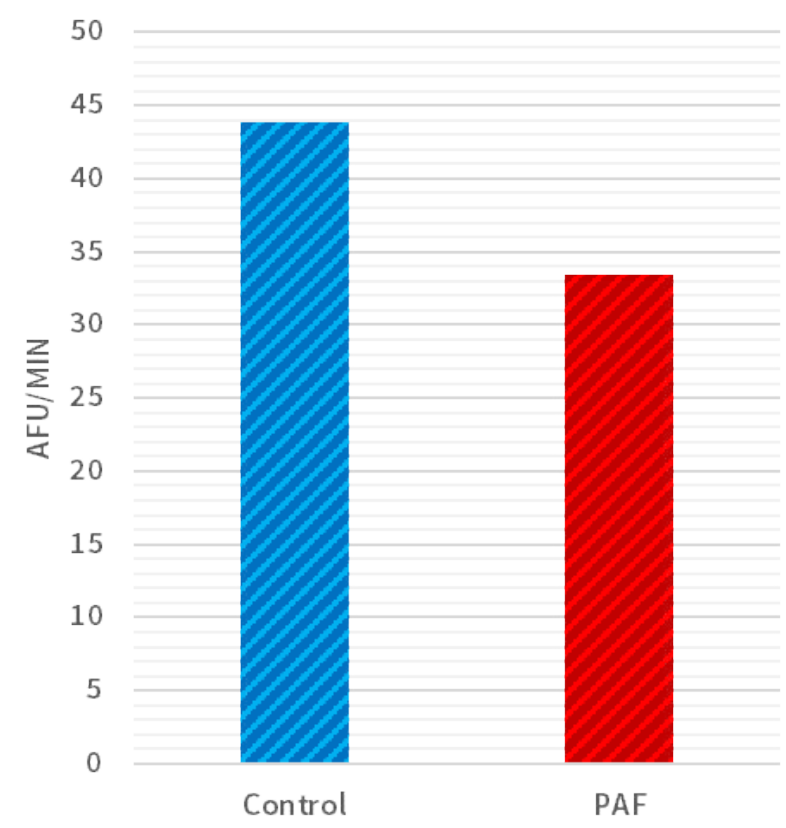

Figure 3. Rate of caspase- 3 activity was lower in PAF treated sea urchins. There was a significant difference $(\mathrm{P}<0.05)$ in caspase-3 enzyme activity between sea urchin embryos cultured in PAF (33.5 [AFU/minute]) versus controls (43.8 [AFU/minute]) as detected by measuring cleavage of the DEVD-AMC peptide via a fluorescent plate reader

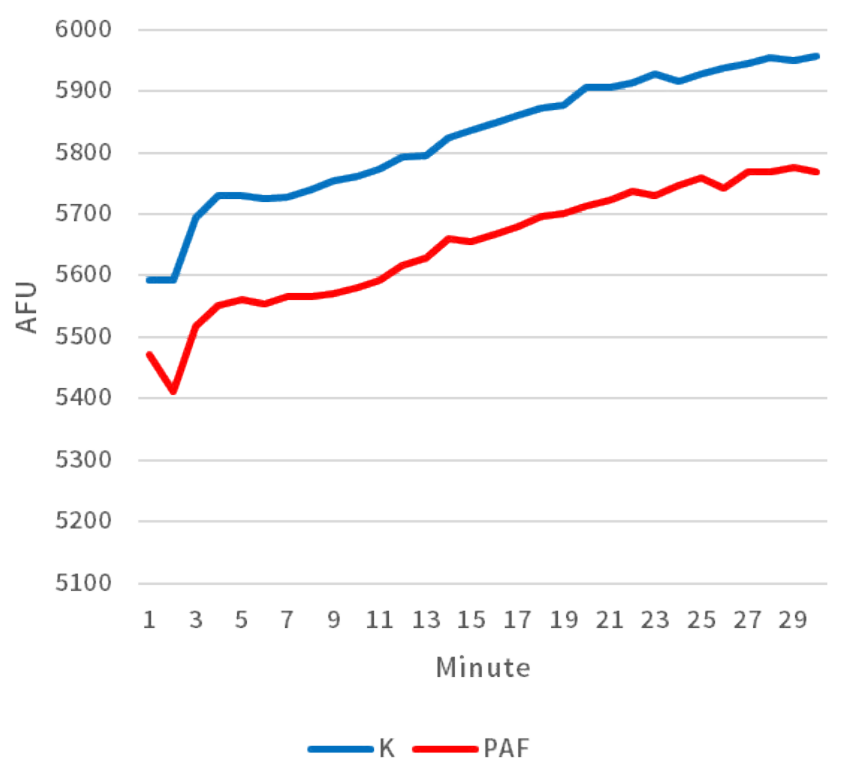

Figure 4. Caspase-3 activity measured over time was lower in sea urchin embryos treated with PAF. The time-dependent graph demonstrates the average levels of caspase-3 activity per treatment group. Sea urchin extract were combined with DEVD-AMC peptide and cleavage of the peptide substrate was measured over time in a fluorescent plate reader

\section{Discussion}

PAF plays many roles in embryology, including an autocrine trophic loop completer, functional embryonic receptor for insulin, and a regulator of apoptotic activity $[11,16,17]$. Moreover, endogenous release of PAF has been found in human embryos [18-21], mouse [22-24], sheep [25], rabbit [9,26], hamster [27], and cow [28] and its production may be an indicator of embryo viability [29]. Yet, PAF appears to have an even more fundamental role than as an endogenous mammalian embryo development enhancer. As per our experiments, the exogenous application of PAF with embryos has both biochemical and morphological implications.

We have demonstrated that sea urchin embryos exposed to exogenous PAF resulted in reduced caspase- 3 activity in the developing embryos. As the rate of caspase- 3 activity correlates to apoptosis, the significantly lower rate of caspase- 3 specific substrate cleavage by extracts implies that sea urchin embryos exposed to PAF exhibited lower levels of apoptosis. Therefore, the introduction of PAF had biochemical implications e.g. inhibition of apoptosis. Nevertheless, morphological and physiological differences also result from the exogenous introduction of PAF. A significantly greater percentage of embryos in the group treated with exogenous PAF developed past the morula stage (which was set as a bar for development by following the expected development rate of previous studies), indicating the effectiveness of PAF as a system for improving embryo survival rates [30]. The embryos in the PAF group also reached later stages of development at significant levels, demonstrating another developmental change associated with the exogenous application.

Additional studies will further elucidate the mechanism by which PAF inhibits apoptotic activity during early embryonic development. Moreover, it is paramount to understand the effects of exogenous PAF on the human embryo-does the decrease in apoptosis also entail any significant potential future harm for the embryo or is it a mechanism for maximizing embryo success?

Nevertheless, the understanding of PAF's selective benefits have significant potential for in vitro fertilization, embryo development and subsequent successful implantation. The current trend in IVF is to minimize multiple embryos for transfer but require optimal embryo development and selection. However, even with selection of embryos via genetic screening, post embryo transfer implantations still have a low percentage of success (less than 60\%), and each failure places challenges financially and emotionally upon couples undergoing IVF [4]. A complete understanding of PAF may permit IVF procedures to produce more high-quality embryos to maximize pregnancy outcomes, thus potentially mitigating the implications of an increasing human infertility problem.

\section{References}

1. Shreffler KM, Greil AL, McQuillan J (2017) Responding to Infertility: Lessons From a Growing Body of Research and Suggested Guidelines for Practice. Fam Relat 66: 644-658. [Crossref]

2. Cui W (2010) Mother or nothing: the agony of infertility. Bull World Health Organ 88: 881-882. [Crossref]

3. Agarwal A, Mulgund A, Hamada A, Chyatte MR (2015) A unique view on male infertility around the globe. Reprod Biol Endocrinol 13: 37. [Crossref]

4. Fragouli E, Munne S, Wells D (2019) The cytogenetic constitution of human blastocysts: Insights from comprehensive chromosome screening strategies. Hum Reprod. Update 25: 15-33. [Crossref] 
5. DeCherney AH (1986) In vitro fertilization and embryo transfer: a brief overview. Yale J Biol Med 59: 409-414. [Crossref]

6. Wang J, Sauer MV (2006) In vitro fertilization (IVF): a review of 3 decades of clinical innovation and technological advancement. Ther Clin Risk Manag 2: 355-364. [Crossref]

7. Edwards LJ, Constantinescu C (2009) Platelet Activating Factor/Platelet Activating Factor Receptor Pathway as a Potential Therapeutic Target in Autoimmune Diseases. Inflammation \& Allergy - Drug Targets (Discontinued) 8: 182. [Crossref]

8. Chao W, Olson MS (1993) Platelet-activating factor: receptors and signal transduction. Biochem J. 292: 617-629. [Crossref]

9. Roudebush WE, Fukuda AI, Minhas BS (1993) Enhanced embryo development of rabbit oocytes fertilized in vitro with platelet activating factor (PAF)-treated spermatozoa. J Assist Reprod Genet. 10: 91-94. [Crossref]

10. Chignard M, Le Couedic JP, Tence M, Vargaftig BB, Benveniste J (1979) The role of platelet-activating factor in platelet aggregation. Nature 279: 799-800. [Crossref]

11. O'Neill C (2005) The role of paf in embryo physiology. Hum Reprod Update 11: 215 228. [Crossref]

12. Weil M1, Jacobson MD, Coles HS, Davies TJ, Gardner RL, et al. (1996) Constitutive expression of the machinery for programmed cell death. J Cell Biol 133: 1053-1059. [Crossref]

13. Brill A, Torchinsky A, Carp H, Toder V (1999) The role of apoptosis in normal and abnormal embryonic development. J Assist Reprod Genet 16: 512-519. [Crossref]

14. Samali A, Fulda S, Gorman AM, Hori O, Srinivasula SM (2010) Cell stress and cell death. Int J Cell Biol 1: 245803. [Crossref]

15. Thurber RV, Epel D (2006) Apoptosis in early development of the sea urchin, Strongylocentrotus purpuratus. Developmental Biology 1: 336-346. [Crossref]

16. Collier M, O'Neill C, Ammit AJ, Saunders DM (1988) Biochemical and pharmacological characterisation of human embryo-derived platelet activating factor. Hum Reprod 3: 993-998. [Crossref]

17. Heyner S, Rao LV, Jarett L, Smith RM (1989) Preimplantation mouse embryos internalize maternal insulin via receptor-mediated endocytosis: pattern of uptake and functional correlations. Dev Biol 134: 48-58. [Crossref]

18. Collier M, O'Neill C, Ammit AJ, Saunders DM (1990) Measurement of human embryo-derived platelet-activating factor (PAF) using a quantitative bioassay of platelet aggregation. Hum Reprod 5: 323-328. [Crossref]
19. Vereecken A, Delbeke L, Angle M, Gielis M, Gerris J, et al. (1990) Embryo-derived platelet activating factor, a marker of embryo quality and viability following ovarian stimulation for in vitro fertilization. J In Vitro Fertil Embryo Transfer 7: 321-326. [Crossref]

20. Nakatsuka M, Yoshida N, Kudo T (1992) Platelet activating factor in culture media as an indicator of human embryonic development after in-vitro fertilization. Hum Reprod 7: 1435-1439. [Crossref]

21. Roudebush WE, Purnell ET, Stoddart NR, Fleming SD (2002a) Embryonic-plateletactivating factor: temporal expression of the ligand and its receptor. $J$ Assist Reprod Genet 19: 72-78.

22. Roudebush WE, Purnell ET, Stoddart NR, Fleming SD (2002a) Embryonicplateletactivating factor: temporal expression of the ligand and its receptor. $J$ Assist Reprod Genet 19: 72-78. [Crossref]

23. Ripps BA, Zhu YP, Burwinkel TH, Kim HN, Buster JE et al. (1993) Platelet-activating factor production from in vitro and in vivo fertilized murine embryos is similar. $\mathrm{Am} \mathrm{J}$ Reprod Immunol. 30: 101-104. [Crossref]

24. Suzuki H, Taguchi Y, Kojima T, Nishihira J, Kanagawa H (1995) Evidence for the production of platelet-activating factor by murine embryos and its putative role in the maternal physiology. Biochem Mol Biol Int 37: 617-626. [Crossref]

25. Battye KM, Ammit AJ, O'Neill C, Evans G (1991) Production of platelet-activating factor by the preimplantation sheep embryo. J Reprod Fertil 93: 507-514. [Crossref]

26. Minhas BS, Zhu Y, Kim H, Burwinkel TH, Ripps BA et al. (1993) Embryonic platelet activating factor production in the rabbit increases during the preimplantation phase. $J$ Assist Reprod Genet. 10: 366-370. [Crossref]

27. Velasquez LA, Aguilera JG, Croxatto HB (1995) Possible role of platelet-activating factor in embryonic signalling during oviductal transport in the hamster. Biol Reprod 52: $1302-1306$.

28. Parks JE, Hough SR (1990) Effect of platelet-activating factor on the motility and acrosome reaction of bovine spermatozoa. Theriogenology 34: 903-912. [Crossref]

29. Roudebush WE, Wininger JD, Jones AE, Wright G, Toledo AA et al. (2002) Embryonic platelet-activating factor: an indicator of embryo viability. Hum Reprod 17: 1306-1310. [Crossref]

30. Gilbert SF (2000) Developmental Biology. 6th edition. Sunderland (MA): Sinaue Associates; 2000. The Early Development of Sea Urchins. [Crossref]

Copyright: $\odot 2019$ Lal A. This is an open-access article distributed under the terms of the Creative Commons Attribution License, which permits unrestricted use, distribution, and reproduction in any medium, provided the original author and source are credited. 